\title{
Controlled Synthesis of Surfactant-Free Water-Dispersible Colloidal Platinum Nanoparticles by the Co4Cat Process
}

Quinson, Jonathan; Kacenauskaite, Laura; Bucher, Jan; Simonsen, Søren B.; Theil Kuhn, Luise; Oezaslan, Mehtap; Kunz, Sebastian; Arenz, Matthias

\section{Published in:}

ChemSusChem

Link to article, DOI:

$10.1002 /$ cssc.201802897

Publication date:

2019

Document Version

Peer reviewed version

Link back to DTU Orbit

Citation (APA):

Quinson, J., Kacenauskaite, L., Bucher, J., Simonsen, S. B., Theil Kuhn, L., Oezaslan, M., Kunz, S., \& Arenz, M. (2019). Controlled Synthesis of Surfactant-Free Water-Dispersible Colloidal Platinum Nanoparticles by the Co4Cat Process. ChemSusChem, 12(6), 1229-1239. https://doi.org/10.1002/cssc.201802897

\section{General rights}

Copyright and moral rights for the publications made accessible in the public portal are retained by the authors and/or other copyright owners and it is a condition of accessing publications that users recognise and abide by the legal requirements associated with these rights.

- Users may download and print one copy of any publication from the public portal for the purpose of private study or research.

- You may not further distribute the material or use it for any profit-making activity or commercial gain

- You may freely distribute the URL identifying the publication in the public portal 


\title{
Controlled synthesis of surfactant-free water-dispersible colloidal platinum nanoparticles by the Co4Cat process
}

\author{
Jonathan Quinson, ${ }^{*[a]}$ Laura Kacenauskaite, ${ }^{[a]}$ Søren B. Simonsen, ${ }^{[b]}$ Luise Theil Kuhn, ${ }^{[b]}$ Mehtap \\ Oezaslan, ${ }^{[\mathrm{c}]}$ Sebastian Kunz ${ }^{[\mathrm{d}]}$ and Matthias Arenz ${ }^{*[\mathrm{e}]}$
}

Abstract: The recently reported Co4Cat process is a synthesis method bearing ecological and economic benefits to prepare precious metal nanoparticles (NPs) with optimized catalytic properties. In the Co4Cat process a metal precursor (e.g. $\mathrm{H}_{2} \mathrm{PtCl}_{6}$ ) is dissolved in an alkaline solution of a low boiling point solvent (methanol) and reduced to NPs at low temperature $\left(<80^{\circ} \mathrm{C}\right)$ without the use of surfactants. We here describe in detail the Co4Cat process to prepare Pt NPs. The advantages of this new synthesis method for research and development, but also industrial production, are highlighted in a comparison with the popular 'polyol' synthesis. The reduction of $\mathrm{H}_{2} \mathrm{PtCl}_{6}$ from $\mathrm{Pt}(\mathrm{IV})$ to $\mathrm{Pt}(\mathrm{II})$ and further to $\mathrm{Pt}(0)$ is followed by UV-vis and XANES/EXAFS measurements. It is demonstrated how the synthesis can be accelerated, how size control is achieved and how the colloidal dispersions can be stabilized without the use of surfactants. Despite being surfactant-free, the Pt NPs exhibit surprisingly long term (up 16 months) stability in water over a wide $\mathrm{pH}$ range (3-12) and in aqueous buffer solutions. The Co4Cat process is thus relevant to produce NPs for heterogeneous catalysis, electro-catalysis or bio/medical applications.

\section{Introduction}

Developing environmentally friendly catalytic processes is at the forefront of more sustainable societies ${ }^{[1]}$ and prosperous industries. ${ }^{[2]}$ Nanotechnologies and in particular nanoparticles (NPs), address worldwide challenges like water remediation, ${ }^{[3]}$ chemical production, ${ }^{[4]}$ energy conversion and storage. ${ }^{[5]}$ Nanotechnologies are also expected to improve biomedical diagnosis and treatments ${ }^{[6]}$ for instance in sensing, imaging or drug delivery.

To ensure the application of a nanotechnology to real business cases, several parameters in the manufacturing of

\footnotetext{
[a] Dr J. Quinson, * Ms L. Kacenauskaite

Department of Chemistry, University of Copenhagen,

Universitetsparken 5, 2100 Copenhagen Ø, Denmark.

E-mail: jonathan.quinson@chem.ku.dk

[b] Dr. S. B. Simonsen, Dr L. Theil Kuhn

Imaging and Structural Analysis, Department of Energy Conversion and Storage, Technical University of Denmark, Frederiksborgvej 399, 4000 Roskilde, Denmark

[c] Prof. Dr. M. Oezalsan

School of Mathematics and Science, Department of Chemistry, Carl von Ossietzky Universität Oldenburg, 26111 Oldenburg, Germany

[d] Dr. S. Kunz

Institute for Applied and Physical Chemistry, University of Bremen Leobenerstraße, 28359 Bremen, Germany

[e] Prof. Dr. M. Arenz

Department of Chemistry and Biochemistry, University of Bern,

Freiestrasse 3, CH-3012 Bern, Switzerland.

E-mail: matthias.arenz@dcb.unibe.ch
}

Supporting information for this article is given via a link at the end of the document. nanomaterials ${ }^{[7]}$ must be controlled from production to processing. (1) Simple, cost-effective, eco-friendly and reliable production methods are needed. (2) The NP size must be controlled because it influences chemical, physical and catalytic properties at the nanoscale. ${ }^{[8]}$ (3) Simple processing of the nanomaterials must be achieved to facilitate their applications, e.g. by achieving (re)dispersion in suitable ${ }^{[9]}$ and ideally 'green' ${ }^{[10]}$ solvents.

To meet the above criteria, wet-chemistry methods ${ }^{[11]}$ like colloidal syntheses, ${ }^{[12]}$ are suitable options because they are compatible with large scale production. ${ }^{\left[{ }^{9 c]}\right]}$ They are also challenging because high boiling point solvents are typically used, which implies energy/resource intensive solvent removal and/or «washing» steps to process the NPs. These steps prevented the large-scale implementation of most colloidal routes.

The 'polyol process' is a popular 'green' synthesis ${ }^{[13]}$ of metal NPs for fundamental research but has not fully found its way to larger scale. Colloidal dispersions are obtained by reduction of a metal complex in an alkaline solution of a polyol to form NPs at high temperature (e.g. > $150{ }^{\circ} \mathrm{C}$ ). Surfactants or polymers like polyvinylpyrrolidone (PVP) are typically added to avoid NP aggregation, achieve size and morphology control or tune colloidal properties like waterdispersibility. ${ }^{[9 b, 13 b, 14]}$ Using additives is an approach equally predominant in the preparation of metal NPs in low boiling point solvents like water, ${ }^{[15]}$ methanol ${ }^{[16]}$ and ethanol ${ }^{[17]}$ or mixture of methanol and water ${ }^{[18]}$ or ethanol and water. ${ }^{[9 b, 19]}$ In conventional approaches no NPs are formed ${ }^{[20]}$ and/or the colloidal solutions in these solvents are unstable without additives.

Developing surfactant-free syntheses is then identified as a key achievement for greener $^{[21]}$ and industrial ${ }^{[22]}$ productions. This is because additives, surfactants or polymers, can be detrimental to the environment. ${ }^{[1-2]}$ Furthermore, additives need to be removed after synthesis because they can negatively affect the catalytic activity. ${ }^{[23]}$ Their removal for instance is key in electrochemistry and related energy applications, ${ }^{[15,24]}$ where fully accessible surfaces for electron transfer are necessary. Equally, from a research and development point of view, the use of additives is disadvantageous. It complicates systematic studies and a thorough testing of hypotheses by adding steps and uncertainties. Common procedures to remove additives are UV-irradiation, harsh thermal and/or chemical treatments $^{[25]}$ which can impair the composition and structure of the as-prepared NPs and may result in limited reproducibility and scalability. ${ }^{[23 a]}$ 
Recent examples support the benefits of surfactant-free syntheses. 'Unprotected' or 'weakly' protected NPs reach competitive catalytic efficiency compared to state-of-theart. ${ }^{[26]}$ For instance Pd NPs prepared in methanol for acetylene hydrogenation ${ }^{[27]}$ and dehydrogenation of formic acid. $^{[21]}$ More efficient precious metal catalysts means a better use of the metal resources.

Yet surfactant-free colloidal dispersions are typically not stable for more than few hours after synthesis. A support material needs to be added after or during synthesis to stabilise the NPs before they agglomerate into undesired lower surface area materials. In such one-pot synthesis, ${ }^{[28]}$ the formation of catalysts into pores of the support cannot be excluded. ${ }^{[29]}$ In the case of precious metal catalysts like platinum $(\mathrm{Pt})$, the 'loading' of the expensive material may then be under-exploited during catalytic operation, which is neither desirable nor sustainable.

Achieving reliable preparation methods of stable colloidal NPs has been a motivation over the years to develop a toolbox for systematic studies of precious metal NPs. ${ }^{[12]}$ Since the pioneering work by Wang et al. ${ }^{[30]}$ it is established that surfactant-free versions of the polyol synthesis lead to stable 'unprotected' colloidal NPs. 'Unprotected' NPs are stabilised by $\mathrm{CO}$ and $\mathrm{OH}^{-}$groups which do not require harsh treatments for removal. ${ }^{[31]}$ The thus obtained NPs are a convenient building blocks to investigate and optimise NPs like Pt for electrocatalysis, ${ }^{[32]}$ sensing $^{[33]}$ or chemical transformations. ${ }^{[34]}$

Alkaline ethylene glycol (EG) has therefore long been considered the most suitable solvent for the widely used polyol process. ${ }^{[13,35]} \mathrm{Pt}$ NPs obtained by this method are typically 1-2 nm in diameter. The small size achieved, even without surfactant, has been inferred to the high viscosity of the solvent preventing NP growth. ${ }^{[13 \mathrm{~b}, 30,36]}$ This same property limits the industrial implementation of the synthesis.

Against expectations from the state-of-the-art, ${ }^{[15-20]}$ we found that a surfactant-free synthesis is possible in low boiling point solvents. In a recent communication, we introduced the 'Co4Cat' (colloids for catalysts) technology that addresses the challenges of colloidal NP synthesis for industrial applications. ${ }^{[26 \mathrm{~b}]}$ In the present work, we compare the Co4Cat process to the popular polyol method to prepare 'unprotected' NPs. We demonstrate that the Co4Cat process combines the advantages of a surfactantfree synthesis with the benefits of low boiling point solvents. For this, we detail the Co4Cat process using alkaline methanol as a green solvent and provide fundamental and practical insights into the synthesis of stable colloidal $\mathrm{Pt}$ NPs.

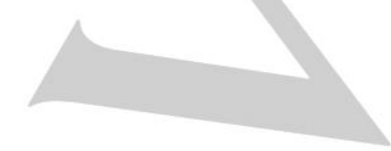

\section{Results and Discussion}

The Co4Cat process: surfactant-free synthesis of Pt NPs in alkaline methanol. Upon heating up an alkaline solution of $\mathrm{H}_{2} \mathrm{PtCl}_{6}$ in a mono-alcohol like methanol, the initially yellow solution turns dark. It takes 2 to 20 minutes of micro-wave irradiation depending on the volume of solution used ( 8 to $80 \mathrm{~mL}, 2.5 \mathrm{mM} \mathrm{H}_{2} \mathrm{PtCl}_{6}, 50 \mathrm{mM} \mathrm{NaOH}$, see also experimental section) to observe this colour change indicating the formation of Pt NPs. A representative transmission electron microscopy (TEM) micrograph of $\mathrm{Pt}$ NPs obtained by the Co4Cat process is shown in Figure 1. Analysis of high resolution TEM micrographs (inset) shows NPs with a fcc crystal structure and a mean size of ca. $2 \mathrm{~nm}$ $(1.8 \pm 0.6 \mathrm{~nm})$. The NP size and size distribution are comparable to the size and size distribution of NPs prepared in alkaline $\mathrm{EG}^{[30,31 \mathrm{~b}]}$ or in mono-alcohols using surfactants (but no base) ${ }^{[9 b]}$ as well as in commercial supported Pt NPs, ${ }^{[37]}$ Figure S1. This NP size is optimal for a range of applications like energy conversion. ${ }^{\left[{ }^{8]}\right.}$

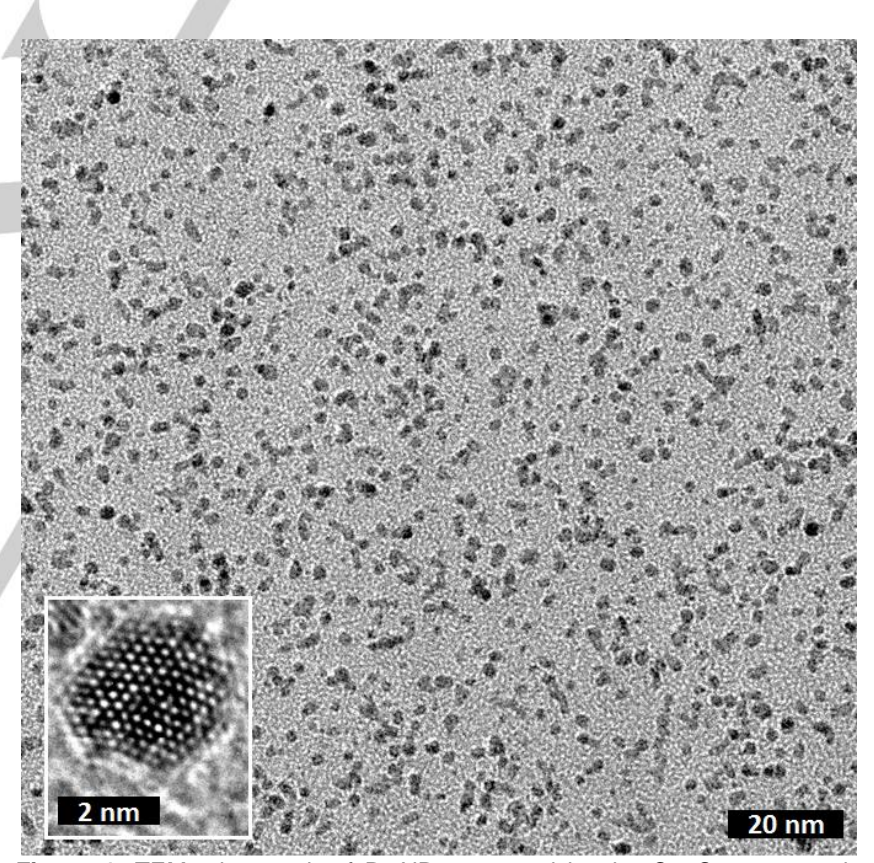

Figure 1. TEM micrograph of Pt NPs prepared by the Co4Cat process in alkaline methanol. The inset is a high resolution TEM micrograph of an individual Pt NP.

Reproducibility and scalability. To demonstrate that the synthesis is relatively fast, reproducible and robust to variations of experimental parameters like $\mathrm{H}_{2} \mathrm{PtCl}_{6}$ concentration and the heating time - factors that become important in a scale up - a series of experiments was performed which results are summarized in Table 1. Different durations for the heating (15 or 60 minutes) and different concentrations of $\mathrm{H}_{2} \mathrm{PtCl}_{6}(0.5,2.0,2.5 \mathrm{mM})$ do not significantly influence the resulting size and size distribution of the NPs; i.e. the size of the particles is always around 2.0 
$\pm 0.5 \mathrm{~nm}$. These results suggest a particle formation mechanism with a fast nucleation and a moderate growth over time. No significant metal leaching and Ostwald ripening occurs over longer heating.

Table 1. Synthesis parameters and resulting size of Pt NPs obtained using a microwave synthesis. The total volume of alkaline methanol was $80 \mathrm{~mL}$. The $\mathrm{NaOH} / \mathrm{Pt}$ molar ratio was 20. Histograms of the size distribution are reported in Figure S2.

\begin{tabular}{ccccccc}
\hline & A & B & C & D & E & F \\
\hline $\mathbf{H}_{2} \mathbf{P t C l}_{6} / \mathbf{m M}$ & 0.5 & 0.5 & 2.0 & 2.0 & 2.5 & 2.5 \\
time / minutes & 15 & 60 & 15 & 60 & 15 & 60 \\
Diameter / nm & 1.9 & 1.9 & 2.1 & 1.6 & 2.1 & 1.9 \\
Deviation / nm & 0.6 & 0.6 & 0.6 & 0.5 & 0.6 & 0.6 \\
\hline
\end{tabular}

General reduction mechanism. To learn more about the general reduction mechanism, the Co4Cat process was investigated by $\mathrm{X}$-ray absorption near edge structure (XANES) and extended X-ray absorption fine structure (EXAFS) measurements. To follow the conversion of Pt(IV) species $(2 \mathrm{mM})$ to metallic $\mathrm{NPs} \operatorname{Pt}(0)$ in alkaline methanol $(10 \mathrm{~mL}, \mathrm{NaOH} / \mathrm{Pt}$ molar ratio of 20$)$, several experiments were performed using a microwave oven, stopped after different times of synthesis and stored in liquid nitrogen prior to measurements, Table 2 (fitting parameters in Table S1). By using a linear combination fitting, the relative quantity of each oxidation state for $\mathrm{Pt}$ species was evaluated as a function of synthesis time from XANES spectra. In a first phase, the starting $\mathrm{Pt}$ (IV) complex $\mathrm{H}_{2} \mathrm{PtC}_{16}$ is gradually reduced to $\mathrm{Pt}(\mathrm{II})$. The time when the solution turns dark brown $(02: 15, \mathrm{~mm}: \mathrm{ss}$ for this set of experiments) matches the time when the $\mathrm{Pt}(\mathrm{II})$ is being converted to $\mathrm{Pt}(0)$. From this point, a second phase of NP growth starts: a Pt-Pt bound signal around $2.5-2.9 \AA$ is observed in the Fourier-transformed $\mathrm{k}^{2}$-weigthed EXAFS spectra reported in Figure 2. This indicates the formation of Pt NPs. The first neighbour coordination shell for Pt-Pt is around 5 as soon as the formation of $\mathrm{Pt}(0)$ starts and increases to 8 after few more minutes of synthesis. This coordination number corresponds to a final size of ca. $2 \mathrm{~nm},{ }^{\left[{ }^{[3]}\right.}$ in agreement with TEM characterisation.

Table 2. Relative percentage of Pt species with different oxidation state obtained by linear combination fitting from XANES data for different time of synthesis. See text for experimental details.

\begin{tabular}{|c|c|c|c|c|c|}
\hline time / mm:ss & $00: 00$ & $00: 30$ & 02:00 & $02: 15$ & $10: 00$ \\
\hline $\mathrm{Pt}(\mathrm{IV}) /$ wt. \% & 100 & $\begin{array}{r}45.6 \\
\pm 2.0 \\
\end{array}$ & $\begin{array}{r}26.1 \\
\pm 0.8 \\
\end{array}$ & $\begin{array}{r}4.6 \\
\pm 2.6 \\
\end{array}$ & 0 \\
\hline $\mathrm{Pt}$ (II) /wt. \% & 0 & $\begin{array}{r}54.4 \\
\pm 2.0\end{array}$ & $\begin{array}{r}73.9 \\
\pm 1.2 \\
\end{array}$ & $\begin{array}{r}39.9 \\
\pm 1.6\end{array}$ & $\begin{array}{r}26.5 \\
\pm 2.1\end{array}$ \\
\hline $\operatorname{Pt}(0) / w t . \quad \%$ & 0 & 0 & 0 & $\begin{array}{r}55.5 \\
\pm 1.1\end{array}$ & $\begin{array}{r}73.5 \\
\pm 2.1\end{array}$ \\
\hline
\end{tabular}


However, an alternative method was found based on the observation that solutions of $20 \mathrm{mM} \mathrm{H}_{2} \mathrm{PtCl}_{6}$ left in methanol for at least a week at ambient conditions (light and room temperature) turn from orange to red-orange, Figure 3. The same 'ageing' effect is achieved by irradiating the $\mathrm{Pt}(\mathrm{IV})$ salt solutions at $20 \mathrm{mM} \mathrm{H}_{2} \mathrm{PtCl}_{6}$ for 30 minutes with UV lamps, Figure S3. This colour change relates to the disappearance of a peak at $268 \mathrm{~nm}$ in the UV absorption spectra of the solutions, indicative of the consumption of the initial $\mathrm{Pt}(\mathrm{IV})$ $\mathrm{Cl}$ complex. ${ }^{[39]}$ Interestingly this peak does not significantly change over time if the solution is kept in the dark. This means that the ageing process leads to a solution with a majority of $\mathrm{Pt}(\mathrm{II})$ species without the formation of $\mathrm{Pt}(0) \mathrm{NPs}$, Table 3 and Figure S4. The aged solutions are stable and can be stored for several months without significant reduction of the $\mathrm{Pt}(\mathrm{II})$ to NPs. It is noteworthy that during the 'ageing' and reduction of $\mathrm{Pt}(\mathrm{IV})$ to $\mathrm{Pt}(\mathrm{II})$ additional chemical changes occur in the $\mathrm{H}_{2} \mathrm{PtCl}_{6}$ solution, i.e. oxidation products of methanol like formic acid and methyl hydrogen carbonate are formed, Figure S5.

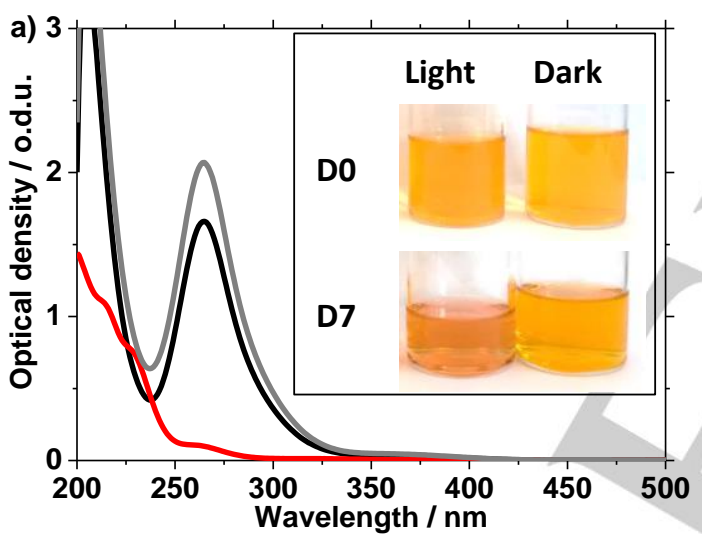

Figure 3. UV-vis absorption spectra after dilution at $0.1 \mathrm{mM}$ of a $20 \mathrm{mM}$ $\mathrm{H}_{2} \mathrm{PtCl}_{6}$ solution in methanol. The grey line corresponds to the as prepared solution on day D0. The red line corresponds to the same sample after a week (D7) at ambient conditions (light and temperature). The black line corresponds to a sample stored in the dark for a week. Inset is images of the various samples on DO and D7.

Table 3. Relative percentage of Pt species with different oxidation state obtained by linear combination fitting from XANES data for a month old solution of $20 \mathrm{mM} \mathrm{H}_{2} \mathrm{PtCl}_{6}$.

\begin{tabular}{lc}
\hline $\mathbf{P t}(\mathrm{IV}) / \%$ & $3.5 \pm 1.2$ \\
\hline $\mathbf{P t}(\mathrm{II}) / \%$ & $96.5 \pm 1.5$ \\
\hline $\mathbf{P t}(0) / \%$ & $0.0 \pm 0.0$ \\
\hline White line intensity & 1.48 \\
\hline$\Delta \mathbf{E}_{0}[\mathrm{eV}]$ & $-0.647 \pm 0.026$ \\
\hline $\mathbf{R}$ & 0.0034 \\
\hline
\end{tabular}

When such 'aged' Pt precursor solutions are used for NP synthesis in alkaline methanol, the formation of NPs is up to 5 times faster as compared to using freshly prepared solutions of precursors. In Figure $4 \mathbf{a}$ the induction period before nucleation of the NPS is especially marked due to the larger volume of solution used $(80 \mathrm{~mL})$ : it takes ca. 20 minutes to observe the NP formation; using an 'aged' solution this time is significantly reduced to 3 minutes. 'Ageing' the precursor $\mathrm{H}_{2} \mathrm{PtCl}_{6}$ before synthesis therefore accelerates the reaction. It does not however influence the size of the NPs, which is still ca. $2 \mathrm{~nm}$ in diameter, Figure 4b. The Co4Cat synthesis is thus robust relative to the age of precursor used: there is no need for freshly prepared $\mathrm{H}_{2} \mathrm{PtCl}_{6}$ solutions. No solutions need to be discarded due to age.

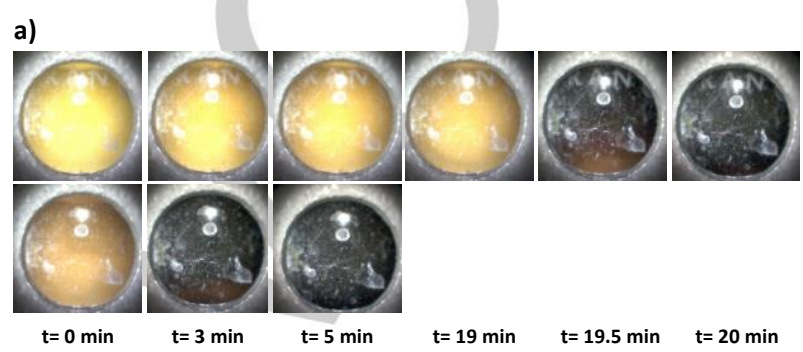

b)

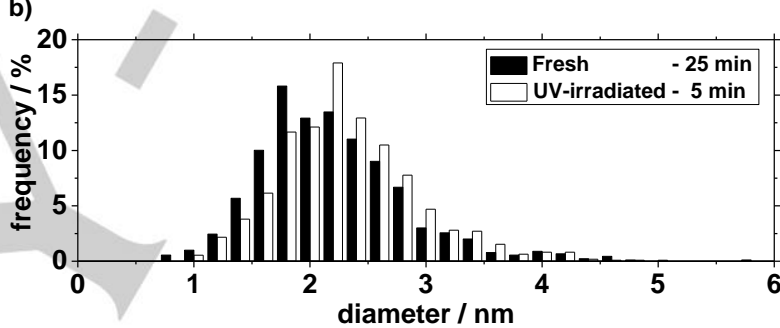

Figure 4. (a) Series of pictures of a reaction mixture at different times for a microwave synthesis with (top) a freshly prepared $\mathrm{H}_{2} \mathrm{PtCl}_{6}$ precursor in methanol and (bottom) a $\mathrm{H}_{2} \mathrm{PtCl}_{6}$ solution in methanol irradiated 30 minutes with UV lamps prior to be mixed with alkaline methanol. All other experimental parameters were the same: $2.5 \mathrm{mM} \mathrm{H}_{2} \mathrm{PtCl}_{6}, 80 \mathrm{~mL}$, $\mathrm{NaOH} / \mathrm{Pt}=20$. (b) Size of the NPs evaluated by TEM.

Size control and influence of water content. In the polyol process the $\mathrm{NaOH} / \mathrm{Pt}$ molar ratio affects the obtained NP size. ${ }^{[26 a, 31 b]}$ To probe a similar effect in alkaline methanol, $2.5 \mathrm{mM}$ and $65 \mathrm{mM} \mathrm{H}_{2} \mathrm{PtCl}_{6}$ solutions in $50 \mathrm{mM} \mathrm{NaOH}$ were prepared. The results show that for $2.5 \mathrm{mM} \mathrm{H}_{2} \mathrm{PtCl}_{6}$ nucleation occurs within few minutes upon heat treatment, whereas for $65 \mathrm{mM} \mathrm{H}_{2} \mathrm{PtCl}_{6}$ the solution remains orange even after 2 hours of heating. The $\mathrm{NaOH} / \mathrm{Pt}$ molar ratio is therefore key to enable the formation of NP in the Co4Cat process. However, once the nucleation proceeds, no strong influence of the $\mathrm{NaOH} / \mathrm{Pt}$ ratio on the NP size is observed. This is in clear contrast to the polyol process, where the $\mathrm{NaOH} / \mathrm{Pt}$ molar ratio allows an accurate control of the size of the NPs. ${ }^{[26 a, 31 b]}$ The $\mathrm{NaOH} / \mathrm{Pt}$ ratio, however, affects the colloidal stability and the formation of agglomerates as is detailed below in parallel to a discussion on colloidal stability. 

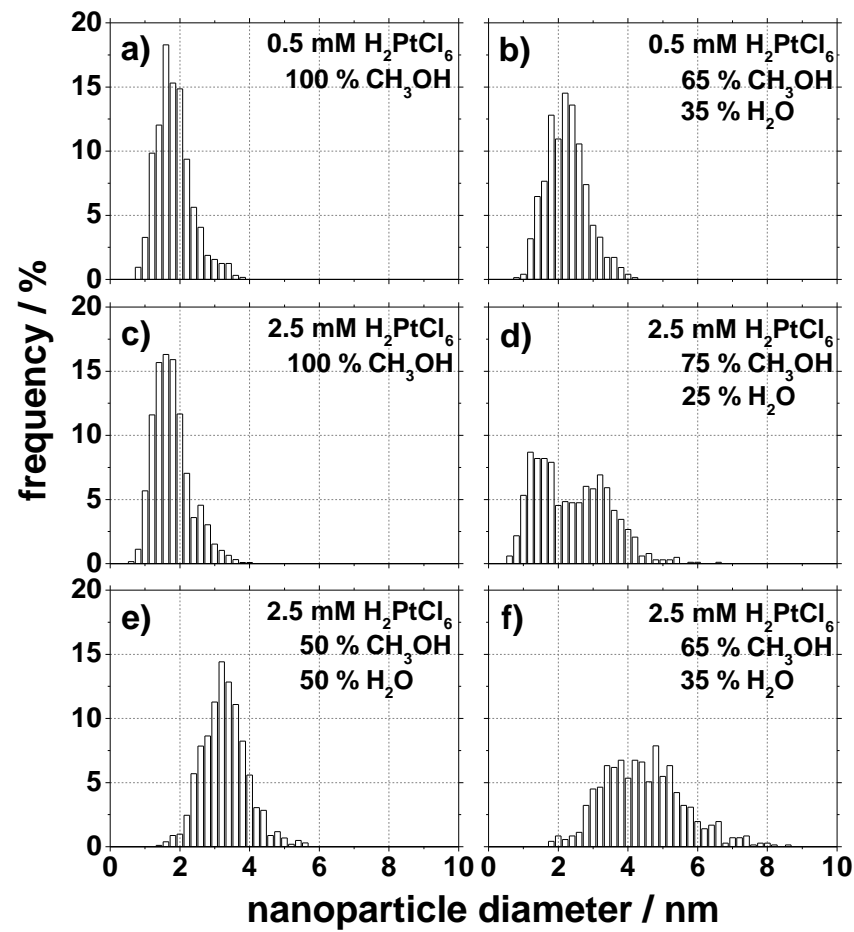

Figure 5. Size estimated by TEM for Pt NPs obtained with different $\mathrm{H}_{2} \mathrm{PtCl}_{6}$ concentration: (a.b) $0.5 \mathrm{mM}$ and (c-f) $2.5 \mathrm{mM}$ in alkaline methanol with different water content (volume \%) of (a, c) $0 \%$, (d) $25 \%$, (e) $50 \%$ and $(b, f) 65 \%$ water. Experimental conditions are detailed in SI.

An alternative way to achieve accurate size control in the Co4Cat synthesis is to add water. ${ }^{[26 b]}$ Here we report the first detailed study on the influence of $\mathrm{H}_{2} \mathrm{PtCl}_{6}$ concentration and water content on the size control of Pt NPs. Water contents in the range 0-100\% were investigated. Figure 5 displays the size distribution evaluated by TEM analysis when water is added to an alkaline methanol reaction mixture (TEM micrographs in Figure $\mathbf{S 6}$ and experimental details in SI). The associated mean diameters are (a) $1.7 \pm$ $0.5 \mathrm{~nm}$, (b) $2.1 \pm 0.6 \mathrm{~nm}$, (c) $1.7 \pm 0.5 \mathrm{~nm}$, (d) $2.3 \pm 1.0 \mathrm{~nm}$, (e) $3.2 \pm 0.7 \mathrm{~nm}$ and (f) $4.4 \pm 1.3 \mathrm{~nm}$, i.e. with the addition of water larger NPs are obtained. This is not surprising and indeed was expected based on our previous report. Our present results, however, demonstrate that the influence of water on the NP size depends on the $\mathrm{Pt}$ precursor concentration. For low $\mathrm{H}_{2} \mathrm{PtCl}_{6}$ concentration $(0.5 \mathrm{mM})$ the water content has little influence on the size of the NPs. Despite adding a significant amount of water to the methanol, the size distribution only exhibits minor changes (Figure 5a,b). Only for larger precursor concentration (2.5 $\mathrm{mM}$, Figure $\mathbf{5 c - f}$ and $25 \mathrm{mM}$, Figure S7) the water content has a pronounced effect: as the water content increases, the NP size increases. The relative standard deviation is typically around $20-40 \%$ regardless of the amount of water used. In the case of $100 \%$ water, no NPs formed even after 60 minutes of synthesis. For an alkaline reaction mixture of $90 \%$ water and $10 \%$ methanol, some NPs formed but the sample is mainly composed of large aggregates, Figure S8. For water content up to $87.5 \%$, colloidal dispersions were obtained.

These results are important to select strategies for size control in the Co4Cat process. A first option is to control the particle size by adding water if the $\mathrm{H}_{2} \mathrm{PtCl}_{6}$ concentration is relatively high (> $2.5 \mathrm{mM}$ ). A second option in alkaline methanol with large amount of water (> $50 \%$ ) is to tune the $\mathrm{H}_{2} \mathrm{PtCl}_{6}$ concentration. A direct consequence is that at lower $\mathrm{H}_{2} \mathrm{PtCl}_{6}$ concentration, the reaction is not very sensitive to the water content. Dry solvents and highly controlled reaction conditions are not necessary to obtain Pt NPs of ca. $2 \mathrm{~nm}$ in diameter.

Analysing the mechanism, it is clear that opposed to the polyol process, ${ }^{[30]}$ the increase in NP size with increasing water content cannot be inferred to a decrease in viscosity. The size distribution obtained for $25 \%$ water in methanol is bi-modal, with two modes of mean particle size values 1.6 and $3.2 \mathrm{~nm}$, Figure $\mathbf{5 b}$. These values correspond to the mean values for syntheses with 0 and $50 \%$ water content, respectively. This suggests a complex influence of the water content on the size control and the growth mechanism. Adding water to achieve size control has been reported in polymer-assisted synthesis in mono-alcohols. ${ }^{[18]}$ Most likely the effect of water on size relates to different kinetics of formation and reaction of hydro-Pt(IV) and hydro$\mathrm{Pt}$ (II) complexes. ${ }^{[18 a]}$ Adding $\mathrm{NaOH}$ to water-methanol mixtures adds an extra degree of complexity and in-situ characterisations are being performed to clarify the detailed reaction pathway. The related results will be the subject of further communication.

The NPs are called 'unprotected', as per the terminology adopted in previous literature. ${ }^{[31]}$ This does not mean they are free of surface groups. Due to the alkaline synthesis procedure, electrostatic NP stabilisation can be achieved by $\mathrm{OH}^{-}$or $\mathrm{CO}$ groups on the NP surface. The FTIR characterisation of Pt NPs obtained by the Co4Cat process presented in Figure 6 shows a typical feature of absorbed CO species on the Pt surface at $2015-2040 \mathrm{~cm}^{-1}$. As expected, it is observed that the wavelength shifts to larger values with increasing particle size (not shown). ${ }^{[31]}$ The $\mathrm{CO}_{\text {ads }}$ originates from the oxidation of methanol on the $\mathrm{Pt}$ surface. Other features in the spectrum can be attributed to methanol or water vapour. The formation of $\mathrm{CO}_{\text {ads }}$ by oxidation at the NP surface might explain the size increase with increasing water content: a small amount of alcohol in high water content mixtures results in a decreased amount of $\mathrm{CO}_{\mathrm{ad}}$ formation (as compared to the pure methanol). This reduced 'CO capping' favours further growth of the NPs and so larger size NPs. 


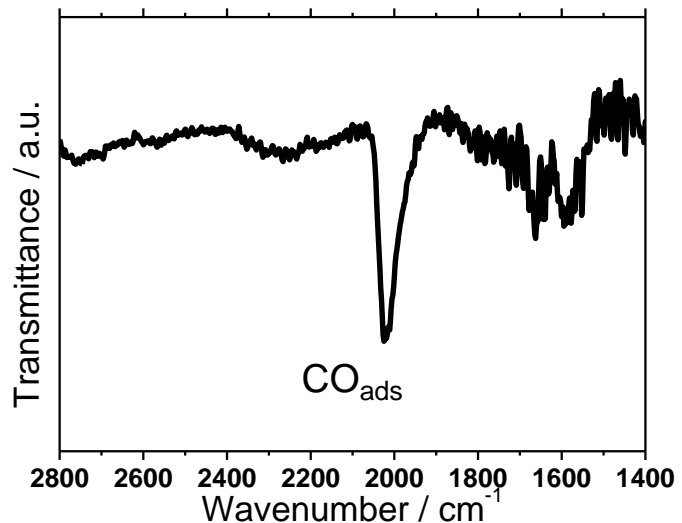

Figure 6. Infra-Red spectra of a Pt NP dispersion obtained by the Co4Cat process in alkaline methanol.

Simple batch and flow syntheses. The combined benefits of a fast synthesis in a low boiling point, low viscosity solvent without addition of surfactants and without the need for inert atmosphere can be exploited in a simple batch as well as in a flow synthesis approach. As a simple batch synthesis process for $\mathrm{Pt}$ NPs alkaline $\mathrm{H}_{2} \mathrm{PtCl}_{6}$ reaction mixtures in a mono-alcohol with or without water are contained in a closed vessel such as a glass vial or plastic tubes and placed in a hot water bath at 70-95 ${ }^{\circ} \mathrm{C}$ (see experimental section). The synthesis is reliable as in a microwave, e.g. NPs with increasing size can be easily obtained by increasing the water content, Figure 7 .

The water bath approach can be implemented in most laboratories since it does not require specific equipment, techniques, knowledge or knowhow. Therefore, the synthesis strategy is especially well-suited for on going insitu studies. The synthesis of 'unprotected' Pt NPs in alkaline EG has been thermally induced in oil bath synthesis, ${ }^{[12]}$ microwave synthesis, ${ }^{[40]}$ at ambient temperature and light ${ }^{[41]}$ or using UV-light. ${ }^{[39]}$ This panel of suitable strategies makes the synthesis highly tuneable for specific needs. The same synthetic approaches are suitable with alkaline mono-alcohols as solvents.

It takes ca. 30 hours at ambient temperature and light to observe a colour change of the reaction mixture from yellow to dark in alkaline methanol $\left(5 \mathrm{~mL}, 2.5 \mathrm{mM} \mathrm{H}_{2} \mathrm{PtCl}_{6}, 50 \mathrm{mM}\right.$ $\mathrm{NaOH}$ ). For UV induced synthesis ca. 30 minutes are required ( $5 \mathrm{~mL}, 2.5 \mathrm{mM} \mathrm{H}_{2} \mathrm{PtCl}_{6}, 50 \mathrm{mM} \mathrm{NaOH}$ ). Pt NPs with a diameter of $2.0 \pm 0.6 \mathrm{~nm}$ at ambient conditions and $1.8 \pm$ $0.5 \mathrm{~nm}$ for UV-induced synthesis are obtained. The NP diameter is similar for NPs obtained by thermally induced synthesis (microwave or oil/water bath synthesis). The Co4Cat process is also applicable to a flow configuration, relevant for industrial production, ${ }^{[42]}$ Figure $\mathbf{S 1 0}$. Low concentration of $\mathrm{H}_{2} \mathrm{PtCl}_{6}$ can be used to get well-defined small size control and continuously produce NPs with high output.

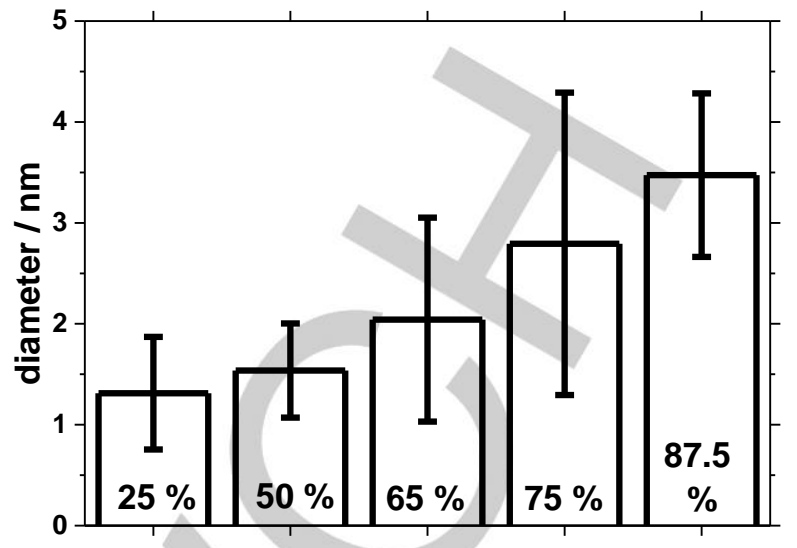

water content / \%

Figure 7. Size distribution estimated by TEM of Pt NPs obtained in alkaline methanol with different water content (as indicated). The $2.5 \mathrm{mM}$ $\mathrm{H}_{2} \mathrm{PtCl}_{6}$ was placed in a closed container heated up in a hot water bath. The NaOH/Pt ratio was 20. TEM micrographs are reported in Figure S9.

The NPs synthesised from a same $\mathrm{H}_{2} \mathrm{PtCl}_{6}$ concentration and same $\mathrm{NaOH}$ concentration in a batch synthesis mode using a microwave, the oil/water bath or a flow process have the same size and size distribution of ca. $2.0 \pm 0.5$ $\mathrm{nm}$, Figure S10. Little dependency of the mode of synthesis is observed for the NP size. The knowledge gained from one synthesis method, e.g. controlling size by adjusting the water content, can be transferred to other synthesis modes to best tune the NPs properties for dedicated applications.

Colloidal stability of as-synthesised colloidal dispersions. Beyond a controlled and flexible synthesis, the stability of as-prepared colloidal suspensions and redispersion properties of nanocatalysts are important for processing and applications. For several NP dispersions prepared in alkaline reaction mixtures (see experimental section and $\mathrm{SI}$ ) the Pt NP size and colloidal stability was investigated after a week, Table 4.

Colloids prepared with the same $\mathrm{H}_{2} \mathrm{PtCl}_{6}$ concentration of $2.5 \mathrm{mM}$ but $\mathrm{NaOH} / \mathrm{Pt}$ molar ratio of $5,20,50$ and 100 , respectively, are listed as entries J, E, G, I. Evidently, the $\mathrm{NaOH} / \mathrm{Pt}$ ratio strongly affects the NP colloidal stability, Figure 8. In the polyol process the $\mathrm{NaOH} / \mathrm{Pt}$ molar ratio needs to be reduced to a value around 3 to obtain a stable colloidal dispersion of NPs with a size of ca. $5 \mathrm{~nm} .^{\text {[26a] }}$ Reducing the $\mathrm{NaOH} / \mathrm{Pt}$ molar ratio to 5 in the Co4Cat process (entry $\mathrm{J}$ ) already exhibits a very poor colloidal stability, i.e. the Pt material sediments due to the formation of larger agglomerates. The agglomerates have a size of approximately $50 \mathrm{~nm}$ but seem to consist of individual NPs with a size of around $5 \mathrm{~nm}$, Figure S11. This indicates that the $\mathrm{NaOH} / \mathrm{Pt}$ ratio influences to some extent the size of the individual NPs but not as markedly as for the EG synthesis. ${ }^{[26 a]}$ Most importantly, the individual NPs are not stabilised against agglomeration. The same happens at high $\mathrm{NaOH} / \mathrm{Pt}$ molar ratios ( $\geq 50$; entries $\mathrm{F}, \mathrm{G}, \mathrm{H}$ and I). 
Also at such conditions most of the NPs sediment. Darkcoloured dispersions indicate that most of the NPs do not sediment and the colloid is stable.

Only for molar ratios in the range of $10 \leq \mathrm{NaOH} / \mathrm{Pt} \leq 20$, stable colloidal dispersions in methanol-water or alkaline methanol mixtures were obtained (for different $\mathrm{H}_{2} \mathrm{PtCl}_{6}$ concentrations or $\mathrm{NaOH}$ concentrations), Figure 8. This relative narrow range of feasible $\mathrm{NaOH} / \mathrm{Pt}$ ratio to synthesise stable colloidal dispersion might explain why previous reports stress that without surfactants (and without a base) no stable colloidal dispersions can be obtained. ${ }^{[16]}$ By using a $\mathrm{NaOH} / \mathrm{Pt}$ of 20 to obtain stable colloidal Pt NP dispersions, as preferred in this study, both the sustainability targets to limit the use of hazardous chemicals and developing safer synthesis - thus making the synthesis cheaper at larger scale - are met.

Table 4. Synthesis parameters and resulting mean size of Pt NPs obtained using a microwave synthesis to heat up for 20 minutes $8 \mathrm{~mL}$ of $\mathrm{H}_{2} \mathrm{PtCl}_{6}$ solutions in $75 \%$ water - $25 \%$ methanol alkaline mixture with different $\mathrm{H}_{2} \mathrm{PtCl}_{6}$ concentrations and $\mathrm{NaOH} / \mathrm{Pt}$ molar ratios.

\begin{tabular}{|c|c|c|c|c|}
\hline Entry & $\mathrm{H}_{2} \mathrm{PtCl}_{6} / \mathrm{mM}$ & $\mathrm{NaOH} / \mathrm{mM}$ & $\mathrm{NaOH} / \mathrm{Pt}$ & Diameter / nm \\
\hline A & 0.5 & 10 & 20 & $2.8 \pm 1.0$ \\
\hline B & 1.0 & 20 & 20 & $3.3 \pm 1.0$ \\
\hline C & 1.5 & 30 & 20 & $2.8 \pm 1.0$ \\
\hline D & 2.0 & 40 & 20 & $2.9 \pm 0-8$ \\
\hline $\mathrm{E}$ & 2.5 & 50 & 20 & $3.0 \pm 0.7$ \\
\hline $\mathrm{F}$ & 1.0 & 50 & 50 & $2.1 \pm 0.6$ \\
\hline $\mathrm{G}$ & 2.5 & 125 & 50 & $2.2 \pm 0.7$ \\
\hline $\mathrm{H}$ & 0.5 & 50 & 100 & $2.1 \pm 0.7$ \\
\hline I & 2.5 & 250 & 100 & $2.0 \pm 0.5$ \\
\hline J & 2.5 & 12.5 & 5 & $5.0 \pm 1.5$ \\
\hline $\mathrm{H}_{2} \mathbf{P t}$ & $\mathrm{I}_{6} / \mathrm{mM}:$ & 1.0 & 1.5 & 2.0 \\
\hline \multicolumn{5}{|c|}{$\mathrm{NaOH} / \mathrm{Pt}=20$} \\
\hline $\mathrm{Na}$ & $\mathrm{H} / \mathrm{Pt}:$ & 20 & 50 & 100 \\
\hline \multicolumn{5}{|c|}{$\mathrm{H}_{2} \mathrm{PtCl}_{6}=2.5 \mathrm{mM}$} \\
\hline \multicolumn{2}{|c|}{ NaOH/Pt : } & 50 & 100 & \\
\hline
\end{tabular}

Figure 8. Pictures of one week old Pt NP colloidal dispersions corresponding to entries $\mathrm{A}$ to $\mathrm{J}$ in Table 4

Re-dispersed colloidal dispersions. Even for the most stable as-synthesised colloidal dispersions prepared by the Co4Cat process, a few Pt NPs sediment within ca. 24 hours. ${ }^{[26 b]}$ However, these sedimented NPs do not sinter but can be collected by centrifugation and re-dispersed, Scheme S1. All the NPs (sedimented and non-sedimented) can also be collected by evaporation of the solvent (e.g. by distillation or using a rotary evaporator). The NPs prepared by the Co4Cat process once collected and re-dispersed are stable more than 9 months in EG, cyclohexanone, methanol, and more surprisingly more than a year in pure water (Milli-Q or de-ionised water). NPs show stability for few months in ethanol and acetone but are not stable more than few hours in isopropanol, n-propanol, n-butanol, tert- butanol, acetonitrile or tetrahydrofuran. This suggests that strong polar solvents are needed for stable re-dispersion. This can be explained based on our current understanding by the stabilisation of the NPs by $\mathrm{CO}$ and $\mathrm{OH} / \mathrm{OH}^{-}$surface groups.

Intense research has been dedicated to ensure the stability of NPs in water. To focus only on the example of Pt NPs, water dispersibility has been achieved with stabilizers like mercaptosuccinic acid, ${ }^{[43]}$ phosphonic derivatives, ${ }^{[44]}$ polymers ${ }^{[45]}$ or carbene. ${ }^{[46]}$ Thus it is quite remarkable that water dispersibility is achieved in the Co4Cat process as a simple surfactant-free approach. The 'unprotected' NPs obtained re-disperse in aqueous solvents, Figure 9, as simple as by shaking the NPs in water and there is no need for sonication to obtain stable dispersions. Even after 16 months of storage, centrifugation at 2400 relative centrifugal force for 10 minutes does not lead to significant sedimentation of the NPs in solution. The NPs do not undergo any size changes even after such an extended storage. The stability of the colloidal dispersions after redispersion is such that they can be shipped without affecting the stability.
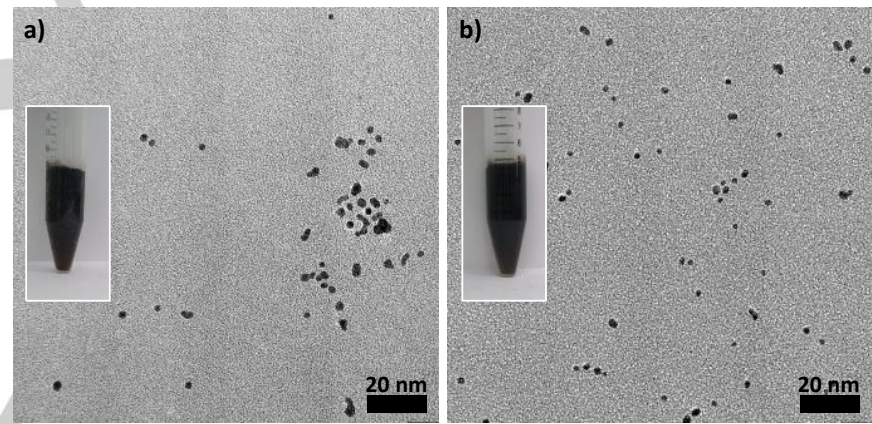

Figure 9. TEM micrographs of (a) as-prepared Pt NPs by the Co4Cat process (diameter $2.9 \pm 0.7 \mathrm{~nm}$ ), (b) the same Pt NPs after storage in Milli-Q water for 16 months $(2.6 \pm 0.7 \mathrm{~nm})$. Inset show the Pt NPs dispersions in water after centrifugation at 2400 relative centrifugal force for 10 minutes.

Influence of acid "washing" on colloidal stability. To identify the origin of the re-dispersibility of the NPs, further comparison with the polyol method was performed. NPs were synthesised by the standard EG synthesis, Figure S1, and re-dispersed in different solvents, Figure 10. The prepared NPs have been characterised previously and have a size of 1-2 nm. ${ }^{[12,26 a, 30]}$ Four solvents for redispersion of the NPs were selected: EG, cyclohexanone, methanol and water (Milli-Q). As expected from the current knowledge on NPs prepared by the EG synthesis ${ }^{[30]}$ the NPs synthesised by the polyol method re-disperse well in EG (a-i) and cylohexanone (a-ii) but do not re-disperse in methanol (a-iii) and water (a-iv). In contrast, the particles synthesised by the Co4Cat process re-disperse in all the solvents (b-i to b-iv). 


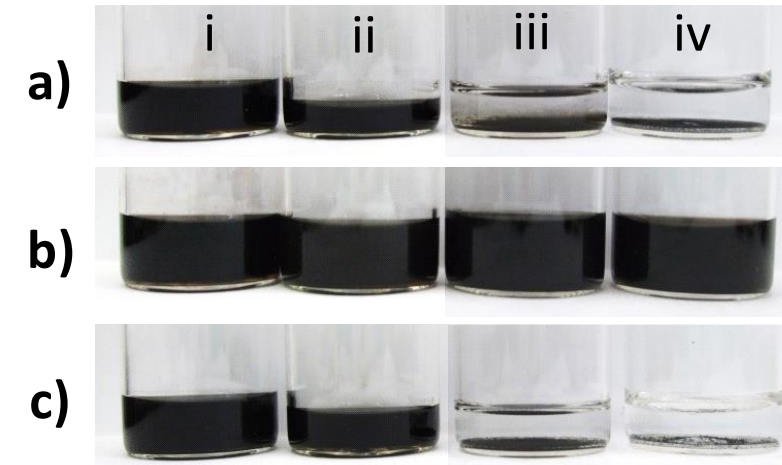

Figure 10. Pt NPs obtained from: (a) synthesis in EG where a "washing" step with $\mathrm{HCl}$ is needed before re-dispersion; (b) Co4Cat synthesis where no "washing» step is needed before re-dispersion; (c) the same as (b) where a «washing» step with $\mathrm{HCl}$ was performed on purpose. Solvents used for re-dispersion are: (i) EG, (ii) cyclohexanone, (iii) methanol, (iv) water (Milli-Q).

Furthermore, as opposed to the polyol-process, the Co4Cat process does not require «washing» steps to process 'unprotected' NPs. In particular there is no need for $\mathrm{HCl}$ «washing»: a poisoning agent for $\mathrm{Pt}^{[47]}$ and an undesirable impurity in a range of fields of applications for nanomaterials. In the polyol synthesis a «washing» step with $1 \mathrm{M} \mathrm{HCl}$ in water is required to collect the NPs. "Washing» of the NPs obtained by the Co4Cat route in $\mathrm{HCl}$ was performed for comparative purposes. It is seen that after such treatment the NPs do not re-disperse in methanol (c-iii) and water (c-iv) anymore, while they still re-disperse in EG (c-i) and cyclohexanone (c-ii). Even after "washing» with large amount of water, the $\mathrm{HCl}$-treated NPs were not re-dispersible in water or alkaline water $(0.1 \mathrm{M} \mathrm{NaOH})$.

During the Co4Cat or polyol synthesis, without using $\mathrm{NaOH}$ NPs form agglomerate, in agreement with previous reports. ${ }^{[16]}$ These agglomerates are not dispersible in water. This supports the role of $\mathrm{OH}^{-}$groups to stabilise the NPs. Possibly the «washing» step in acid reduces the amount of $\mathrm{OH}^{-}$groups on the NPs surface which reduces the stability of the NPs in low viscosity solvents like water and methanol. The only way to re-disperse NPs obtained by the EG synthesis in aqueous solutions is to perform a phase extraction in an alkaline water solutions from an organic solvent after several «washing» steps. ${ }^{[48]}$ Thus, water dispersibility is achieved in the Co4Cat process in a much direct way.
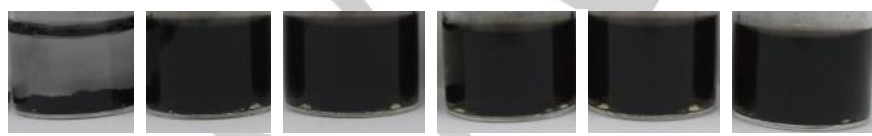

Figure 11. Colloidal dispersions of Pt NPs obtained by the Co4Cat process re-dispersed in (from left to right): $10 \mathrm{mM} \mathrm{HCl}, 1 \mathrm{mM} \mathrm{HCl}, 0.1$ $\mathrm{mM} \mathrm{HCl}, 1 \mathrm{mM} \mathrm{NaOH}, 10 \mathrm{mM} \mathrm{NaOH}, 100 \mathrm{mM} \mathrm{NaOH}$ (all aqueous solutions). Dispersions are stable for at least 10 months. The dispersion at $10 \mathrm{mM} \mathrm{HCl}$ sedimented after 24 hours and illustrates an unstable dispersion.
Re-dispersibility in aqueous buffers. In 'real-life' applications, like medical applications, it is not in pure water that NPs need to be re-dispersed, but in complex media with different ionic strength and $\mathrm{pH}$. To test the bioapplicability of NPs obtained by the Co4Cat process, we investigated the re-dispersion properties of $\mathrm{Pt} N P s$ in aqueous buffers. We found that the re-dispersed NPs obtained by the Co4Cat process are stable for several months in the $\mathrm{pH}$ range 3-12: $1 \mathrm{mM} \mathrm{HCl}$ to $100 \mathrm{mM} \mathrm{NaOH}$, Figure 11. Stability for this range of $\mathrm{pH}$ is rather unexpected for 'unprotected' NPs. The stability is not much limited by $\mathrm{pH}$ range but affected by different ionic force. For instance, no stability was observed using tap water with uncontrolled ionic strength. When the ionic force increases the NP stability decreases. Stability up to a month was observed in $50 \mathrm{mM}$ aqueous sodium phosphate buffer at $\mathrm{pH} 7$, even longer stability of at least 8 months in a $10 \mathrm{mM}$ buffer. Similar stability behaviour was observed for 8 months in $25 \mathrm{mM}$ aqueous $\mathrm{NaCl}$. These results stress the importance of electrostatic stabilisation of unprotected NPs. It also stresses the strategic features of the Co4Cat process for catalysis in aqueous solutions ${ }^{[9 b]}$ or bio/medical applications. $\left.{ }^{[9 a}, 49\right]$

Towards simple preparation of supported catalysts. To collect the NPs in the Co4Cat process, distillation of the low boiling point mono-alcohol is enough: no «washing» steps and no strong acid are needed. The solvent can be recovered at ca. $94 \%$ and re-used. ${ }^{[26 b]}$ While the solvent recovery is performed, a solid powder is obtained suitable for isolation, storage and re-use of the unprotected NPs. ${ }^{[48]}$ While this evaporation step is performed, a support material (e.g. carbon, alumina, silica, etc.) can be added to the colloidal solutions to obtain supported surfactant-free catalysts. Supports can also be added during the synthesis while the NPs are formed for one-pot preparation of heterogeneous catalysts or electrodes, Figure 12. The removal of the solvent is in all cases simpler than for the EG synthesis due to the lower boiling point of monoalcohols.
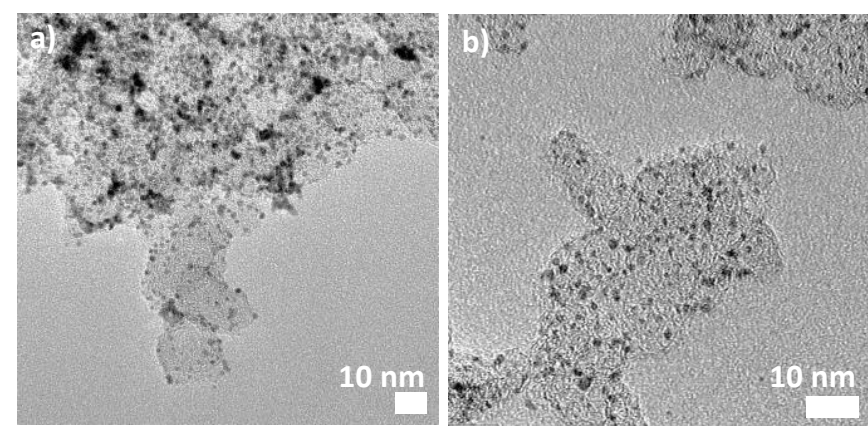

Figure 12. TEM micrographs of: (a) Pt NPs (diameter $2.2 \pm 0.6 \mathrm{~nm}$ ) synthesised in alkaline methanol for which the solvent was evaporated after NP synthesis in presence of a carbon support $(2.1 \pm 0.7 \mathrm{~nm})$, (b) NPs directly synthesised in presence of a carbon support using ethanol as solvent $(2.2 \pm 0.9 \mathrm{~nm})$. 


\section{Conclusions}

The Co4Cat process is a flexible synthesis tool to match both academic and industrial specific needs in the preparation of surfactant-free metal NPs. It is well-suited to synthesise precious metal NPs like Pt and shows multiple benefits compared to syntheses using mono-alcohols with surfactants or the popular polyol synthesis with or without surfactants. The Co4Cat process is flexible and displays promising features for fast and large-scale production of precious metal NPs. It generates minimal waste as compared to the polyol synthesis and avoids the use of energy demanding solvent-removal steps and strong acids for collection of the NPs. There is no need for freshly prepared precursor solutions, anhydrous conditions or controlled atmosphere as in other synthesis routes. ${ }^{[21,27]}$ Despite being surfactant-free, the Co4Cat process allows designing catalysts with controlled size and long-term redispersion properties for instance in aqueous solvents.

Metal NPs prepared by the Co4Cat process were shown to have competitive activity compared to state-of-the-art catalysts for heterogeneous and electrocatalysis and the technology is suitable to prepare bi-metallic nanomaterials. ${ }^{[26 \mathrm{~b}]}$ It is expected that the practical and fundamental insights given in this report on NP synthesis by the Co4Cat technology and dispersion of these NPs will be beneficial to design efficient catalysts in these fields but also for sensing, imaging or bio/medical applications.

\section{Experimental Section}

\section{Chemicals and support materials}

All chemicals were used as received: $\mathrm{H}_{2} \mathrm{PtCl}_{6} \cdot 6 \mathrm{H}_{2} \mathrm{O}(99.9 \%$ Alfa Aesar); $\mathrm{K}_{2} \mathrm{PtCl}_{6}$ (99.9\% Alfa Aesar); $\mathrm{K}_{2} \mathrm{PtCl}_{4}$ (99.9\% Alfa Aesar); $\mathrm{NaOH}$ (98\%, Alfa Aesar or > 99\%, Carl Roth $\mathrm{GmbH})$; ethylene glycol (99+\%, Sigma-Aldrich); methanol ( $\geq$ $99.8 \%$, Sigma-Aldrich); ethanol (99.9\%, Kemetyl); water (Milli-Q, Millipore, resistivity > $18.2 \mathrm{M} \Omega \cdot \mathrm{cm}$, total organic carbon (TOC) $<5 \mathrm{ppb}$ ); $1 \mathrm{M} \mathrm{HCl}$ (Suprapur $\AA$, EMD Millipore, Merck KGaA); $\mathrm{NaHPO}_{4}(\geq 99.0 \%$, Sigma); $\mathrm{Na}_{2} \mathrm{PO} 4$ ( $\geq 99.0 \%$, Sigma); $\mathrm{HNO}_{3}$ (65\%, Suprapur®, EMD Millipore, Merck KGaA); $\mathrm{NaCl}$ (ReagentPlus $\AA, \geq 99 \%$ ); carbon support (Vulcan XC72R, Cabot Corporation, BET area: $235 \mathrm{~m}^{2} \mathrm{~g}^{-1}$ ).

\section{Synthesis procedures}

General synthesis of Pt NPs in mono-alcohols. The metal salt $\mathrm{H}_{2} \mathrm{PtCl}_{6} .6 \mathrm{H}_{2} \mathrm{O}$ is dispersed in alkaline $\mathrm{NaOH}$ methanol or ethanol with concentration of $\mathrm{H}_{2} \mathrm{PtCl}_{6} \cdot 6 \mathrm{H}_{2} \mathrm{O}$, concentration of $\mathrm{NaOH}$, total volume and time of experiment as indicated in the text. Unless otherwise specified all experiments were performed with a $\mathrm{NaOH} / \mathrm{Pt}$ molar ratio of 20 . This ratio was fond to be suitable to (1) enable the formation of Pt NPs and (2) lead to stable colloidal dispersions.

The formation of the Pt NPs can be initiated by leaving the reaction mixture at ambient conditions for several days, by UV-irradiation or thermal irradiation. Controlling the heating up and cooling down of the reaction mixture is easier using a microwave oven: unless otherwise specified the NPs were obtained using a microwave as described below.

Synthesis of Pt NPs in ethylene glycol. The synthesis of NPs in ethylene glycol (EG) followed our previously reported recipe ${ }^{[12]}$ adapted to a micro-wave oven synthesis. ${ }^{[50]}$ The solution of $\mathrm{H}_{2} \mathrm{PtCl}_{6}(20 \mathrm{mM})$ in alkaline $(0.2 \mathrm{M} \mathrm{NaOH}) \mathrm{EG}$ was heated up in a close flask using a microwawe oven at $160^{\circ} \mathrm{C}$ for 3 minutes.

\section{Materials and methods}

UV induced synthesis. Ten standard UV mercury lamps (PL-L-24W/10/4P Hg, Philips) were used to irradiate the solution mixture placed in a sealed glass vials.

Oil bath synthesis. An oil bath heated at $75^{\circ} \mathrm{C}$ (and stirred at $1000 \mathrm{rpm}$ with a magnetic stirrer) was used and the reaction mixture, stirred with a magnetic stirrer at $1000 \mathrm{rpm}$, placed in a round flask connected to a reflux set up.

Microwave synthesis. The reaction mixture was irradiated with a constant power of $100 \mathrm{~W}$ using a microwave oven (CEM Discover SP). The synthesis time is indicated in the text. While the solution was irradiated, a flow of $\mathrm{N}_{2}$ was passed on the outside of the vessel to cool it down, otherwise the temperature raised too quickly. No stirring was performed.

Hot water bath synthesis. Plastic (alternatively glass) vials (without magnetic stirrers) containing $8 \mathrm{~mL}$ of $2.5 \mathrm{mM}$ $\mathrm{H}_{2} \mathrm{PtCl}_{6}$ in methanol-water mixtures (water content from 00 $\%$ to $87.5 \%$ ) were placed in a hot water bath. The water bath was first heated up at $60{ }^{\circ} \mathrm{C}$ but it then takes more than 120 minutes to see any colour change in the reaction mixtures. The temperature was gradually increased from $60^{\circ} \mathrm{C}$ to $95^{\circ} \mathrm{C}$ with a hold step of one hour each time a reaction mixture turned dark, the solution was removed from the bath. As the water content increases the temperature to reach to observe a colour change, indicative of NP nucleation, increases.

pH. $\mathrm{pH}$ of solutions was measured using a $\mathrm{pH}$ meter (Symphony SP70P, VWR) with a glass electrode (InLab Routine, Mettler Toledo). $\mathrm{pH}$ of solutions was adjusted using $\mathrm{HCl}$ or $\mathrm{NaOH}$ solutions. Buffers were obtained mixing $\mathrm{NaHPO}_{4}$ and $\mathrm{Na}_{2} \mathrm{PO} 4$ aqueous solutions at 10 or $100 \mathrm{mM}$.

Centrifuge. A 2400 relative centrifugal force $(4000$ rotations per minute, Sigma 2-5) was used for 5 to 10 minutes for all centrifugation steps for assessment of colloidal stability or «washing» procedures.

Ageing of precursor. To artificially ageing the solutions of $\mathrm{H}_{2} \mathrm{PtCl}_{6}$, the solutions were exposed for 30 minutes to the light of ten standard UV mercury lamps (PL-L-24W/10/4P 
$\mathrm{Hg}$, Philips). Alternatively, the solutions were left at ambient conditions and light for at least a week. Unless otherwise specified, freshly (daily) prepared precursor solutions were used in all syntheses.

\section{Characterisation}

UV-vis absorption characterisation. UV-vis absorption spectra were acquired with a Lambda UV/VIS/NIR absorption spectrometer, Perkin Elmer by diluting the desired solution to a suitable concentration for spectroscopic measurements (typically $0.1 \mathrm{mM}$ ) and using the same solvent (e.g. methanol) for background and measurements.

Determination of particle size distributions by transmission electron microscopy (TEM). For TEM analysis a JEOL 2100 microscopes operated at $200 \mathrm{kV}$ was used. For high resolution TEM a JEOL $3000 \mathrm{~F}$ equipped with a FEG and operated at $300 \mathrm{kV}$ was used. Size and morphology were estimated by recording images at three different magnification (at least $\times 300000, x 400$ 000, x500 $000)$ in at least three randomly selected areas. The samples were prepared by dropping the solutions containing the NPs and low boiling point solvent (e.g. methanol) on carbon coated copper TEM grids (Quantifoil). The particle size and size distribution analysis was performed by measuring the size (diameter) of at least 200 and more typically between 700 and 1000 NPs using the software ImageJ. The mean diameter and the standard deviation for each sample are reported.

From high resolution TEM images crystal with zone axis orientation were analysed by using the software CrystalMatch to assess that all measured lattice planes and their intersection angles were consistent with the $\mathrm{Pt} f c c$ zone axis within an error of $10 \%$ for measured distances and $5 \%$ for measured angles (estimated by analysis of 11 crystals images)

Redispersion studies. For re-dispersion studies, NPs that sediment after 24 hours from as-prepared colloidal solutions were separated from the supernatant by centrifugation and re-dispersed in the desired solvent. Alternatively, all the NPs produced were used after removing the solvent chosen for synthesis by distillation or using a rotary evaporator. The stability of the re-dispersion was followed over time and pictures taken at least on a weekly basis. A dispersion was considered stable if the supernatant maintained a brown or dark colour and no significant sedimentation of NPs was observed at the bottom of the vials. The concentration of Pt NPs typically used for re-dispersion vary between 0.1 and $0.5 \mathrm{~g} \mathrm{~L}^{-1}$ based on ICP-MS measurements performed as previously documented. ${ }^{[51]}$

XAS measurements. XAS measurements were carried out at the Diamond Light Source (DLS), UK and Swiss Light Source, Switzerland, using the B18 and SuperXAS beam line, respectively. The storage ring of the DLS and SLS was operated at a beam current of 300 and $400 \mathrm{~mA}$, respectively, and the storage ring energies were 3.0 and $2.4 \mathrm{GeV}$, respectively. At the B18 beam line, the $\mathrm{Pt} \mathrm{L}_{3}$ egde XAS spectra were recorded in fluorescence mode by using a 9 element $\mathrm{Ge}$ solid state detector system, while the acquisition of the $\mathrm{Pt}_{3}$ edge XAS spectra was performed in transmission mode at the SuperXAS beam line by using $\mathrm{N}_{2-}$ filled ionization chambers with lengths of 15 and $30 \mathrm{~cm}$ for the incident $\left(I_{0}\right)$ and transmitted $\left(I_{1}\right.$ and $\left.I_{2}\right)$ X-ray intensities. The averaged XAS spectra were then analysed by using the IFEFFIT software suite. ${ }^{[52]}$ All spectra were background subtracted and normalized. The energy units $(\mathrm{eV})$ were converted to photoelectron wave vector $k$ units $\left(\AA^{-1}\right)$ by assigning the photoelectron energy origin, $E_{0}$, corresponding to $k=0$, to the first inflection point of the absorption edge. The resulting $\mathrm{X}(\mathrm{k})$ functions were weighted with $k^{2}$ to compensate for the dampening of the XAFS amplitude with increasing $k$. The resulting EXAFS spectra then were Fourier-transformed to obtain pseudo radial structure functions (RSFs).

To estimate the amplitude reduction factor $\left(\mathrm{S}_{0}^{2}\right)$, a Pt foil was used as reference. The coordination number $(N)$, interatomic bond length $(R)$, mean squared bond length disorder $\left(\sigma^{2}\right)$ and correction to the energy origin $\left(\Delta E_{0}\right)$, together with their error bars were established for each sample by fitting theoretical EXAFS signal to the data in $r$ space. The linear fit combination method was carried out to establish the oxidation state of $\mathrm{Pt}$ species in the liquid by using the respective XANES spectra from $\mathrm{K}_{2} \mathrm{PtCl}_{4}, \mathrm{~K}_{2} \mathrm{PtCl}_{6}$ and $\mathrm{Pt}$ foil as reference.

Head-space gas chromatography-mass spectroscopy (GC-MS).

A headspace sampler (Agilent G1888 Network Headspace Sampler) connected to a gas chromatograph (Agilent $6890 \mathrm{~N}$ Network GC System) with a mass spectrometer (Agilent 5973 inert Mass Selective Detector) was used for the analysis. An Agilent 19091S-433 non-polar column was used (HP-5ms (5\%-phenyl) methyl poly siloxane, $30.0 \mathrm{~m}$, $250 \mu \mathrm{m}, 0.25 \mu \mathrm{m})$. Chromatographs were recorded using a temperature ramp from 30 to $140{ }^{\circ} \mathrm{C}$ at $20^{\circ} \mathrm{C} \mathrm{min}{ }^{-1}$.

\section{Infra-Red spectroscopy.}

The as-prepared Pt NPs in alkaline $(\mathrm{NaOH})$ methanol were dropped onto a ZnSe ATR crystal. An alkaline $(\mathrm{NaOH})$ solution of methanol was used as background. The IR spectra were recorded in ATR mode on a Thermo-Nicolet Avatar $370 \mathrm{FT}-\mathrm{IR}$ spectrometer. All spectra were recorded with a resolution of $4 \mathrm{~cm}^{-1}$ and taking 50 scans.

\section{Acknowledgements}

M.A. acknowledges the support from the Villum Foundation. J.Q. received funding from the European Union's Horizon 
2020 research and innovation programme under the Marie Skłodowska-Curie grant agreement No 703366 (SELECTRON). Dr Tom Vosch is acknowledged for fruitful discussion. B. J. Davis is thanked for her help with GC-MS; S. Neumann for IR data acquisition. M.O thanks the Federal Ministry of Education and Research (BMBF, FKZ 03SF0539) for financial support. Matthew Johnson, Bo Wegge Laursen and Thomas Just Sørensen are thanked for use of equipment. Diamond Light Source, Hartwell, UK is thanked - in particular Dr Giannantonio Cibin and AnnKathrin Geiger - for access to synchrotron beamline B18 (proposal SP12746). The Swiss Light Source (SLS) at the Paul Scherrer Institute, Switzerland is thanked - in particular Dr Maarten Nachtegaal and Dr Olga Safonava - for access to synchrotron beamline SuperXAS (proposal 20161303).

Keywords: Co4Cat technology • Colloids • Nanoparticles • Water-dispersibility $\bullet$ Synthesis

[1] H. H. Duan, D. S. Wang, Y. D. Li, Chem. Soc. Rev. 2015, 44 5778-5792.

[2] S. Olveira, S. P. Forster, S. Seeger, J. Nanotechnol. 2014, Article ID 324089 .

[3] T. Pradeep, Anshup, Thin Solid Films 2009, 517, 6441-6478.

[4] Y. Wang, J. L. Zhang, X. D. Wang, J. W. Ren, B. J. Zuo, Y. Q. Tang, Top. Catal. 2005, 35, 35-41.

[5] S. Basri, S. K. Kamarudin, W. R. W. Daud, Z. Yaakub, Int. J. Hydrogen Energy 2010, 35, 7957-7970.

[6] M. Rai, A. P. Ingle, S. Birla, A. Yadav, C. A. Dos Santos, Crit. Rev. Microbiol. 2016, 42, 696-719.

[7] a) C. A. Charitidis, P. Georgiou, M. A. Koklioti, A.-F. Trompeta, V. Markakis, Manuf. Rev. 2014, 1; b) T. Tsuzuki, Int. J. Nanotechnol. 2009, 6, 567-578.

[8] E. Antolini, Appl. Catal. B. 2016, 181, 298-313.

[9] a) J. B. Mamani, L. F. Gamarra, G. E. D. Brito, Mater Res-lberoAm. J. 2014, 17, 542-549; b) C. W. Chen, D. Tano, M. Akashi, J. Colloid Interface Sci. 2000, 225, 349-358; c) Y. Holade, N. E. Sahin, K. Servat, T. W. Napporn, K. B. Kokoh, Catalysts 2015, 5 , 310-348.

[10] D. Prat, A. Wells, J. Hayler, H. Sneddon, C. R. McElroy, S. Abou Shehada, P. J. Dunn, Green Chem. 2016, 18, 288-296.

[11] F. J. Zhu, J. Kim, K. C. Tsao, J. L. Zhang, H. Yang, Curr. Opin. Chem. Eng. 2015, 8, 89-97.

[12] J. Speder, L. Altmann, M. Roefzaad, M. Baumer, J. J. K. Kirkensgaard, K. Mortensen, M. Arenz, Phys. Chem. Chem. Phys. 2013, 15, 3602-3608

[13] a) H. Dong, Y. C. Chen, C. Feldmann, Green Chem. 2015, 17, 4107-4132; b) F. Fievet, S. Ammar-Merah, R. Brayner, F. Chau, M. Giraud, F. Mammeri, J. Peron, J.-Y. Piquemal, L. Sicarda, G. Viaub, Chem. Soc. Rev. 2018, 47, 5187-5233.

[14] J. Cookson, Platin. Met. Rev. 2012, 56, 83-98.

[15] J. Y. Park, C. Aliaga, J. R. Renzas, H. Lee, G. A. Somorjai, Catal. Lett. 2009, 129, 1-6.

[16] C.-S. Lin, M. R. Khan, S. D. Lin, J. Colloid Interface Sci. 2006 299, 678-685

[17] A. Dandapat, A. Mitra, P. K. Gautam, G. De, Nanomater Nanotechno. 2013, 3 .

[18] a) S. M. Chen, Q. Y. Yang, H. H. Wang, S. Zhang, J. Li, Y. Wang, W. S. Chu, Q. Ye, L. Song, Nano Lett. 2015, 15, 5961-5968; b) T. Teranishi, M. Hosoe, T. Tanaka, M. Miyake, J. Phys. Chem. B. 1999, 103, 3818-3827.

[19] a) Y. Y. Li, J. Han, L. P. Jiang, F. Y. Li, K. Li, Y. H. Dong, Anal. Lett. 2015, 48, 1139-1149; b) M. Harada, N. Tamura, M. Takenaka, J. Phys. Chem. C. 2011, 115, 14081-1409.

[20] H. Hirai, Y. Nakao, N. Toshima, Chem. Lett. 1978, 545-548.

[21] Q. L. Zhu, N. Tsumori, Q. Xu, J. Am. Chem. Soc. 2015, 137, 11743-11748.

[22] P. T. Witte, P. H. Berben, S. Boland, E. H. Boymans, D. Vogt, J. W. Geus, J. G. Donkervoort, Top. Catal. 2012, 55, 505-511.

[23] a) Z. Q. Niu, Y. D. Li, Chem. Mater. 2014, 26, 72-83; b) W. X Huang, Q. Hua, T. Cao, Catal. Lett. 2014, 144, 1355-1369.
[24] a) N. Naresh, F. G. S. Wasim, B. P. Ladewig, M. Neergat, J. Mater. Chem. A. 2013, 1, 8553-8559; b) W. Liu, H. L. Wang, Surf. Sci. 2016, 648, 120-125.

[25] M. A. Montiel, F. J. Vidal-Iglesias, V. Montiel, J. Solla-Gullon, Curr. Opin. Electrochem. 2017, 1, 34-39.

[26] a) J. Quinson, M. Inaba, S. Neumann, A. Swane, J. Bucher, S. Simonsen, L. Theil Kuhn, J. Kirkensgaard, K. Jensen, M. Oezaslan, S. Kunz, M. Arenz, ACS Catal. 2018, 8, 6627-6635; b) J. Quinson, S. Neumann, T. Wannmacher, L. Kacenauskaite, M. Inaba, J. Bucher, F. Bizzotto, S. B. Simonsen, L. T. Kuhn, D. Bujak, A. Zana, M. Arenz, S. Kunz, Angew. Chem. 2018, 130 12518-12521; Angew. Chem. Int. Ed. 2018, 57, 12338-12341.

[27] P. D. Burton, T. J. Boyle, A. K. Datye, J. Catal. 2011, 280, 145149.

[28] B. I. Kharisov, H. V. R. Dias, O. V. Kharissova, A. Vazquez, J. Nanoparticle Res. 2014, 16.

[29] Y. C. Park, H. Tokiwa, K. Kakinuma, M. Watanabe, M. Uchida, J. Power Sources 2016, 315, 179-191.

[30] Y. Wang, J. W. Ren, K. Deng, L. L. Gui, Y. Q. Tang, Chem.Mater 2000, 12, 1622-1627.

[31] a) I. Schrader, J. Warneke, S. Neumann, S. Grotheer, A. A. Swane, J. J. K. Kirkensgaard, M. Arenz, S. Kunz, J. Phys. Chem. C. 2015, 119, 17655-17661; b) E. A. Baranova, C. Bock, D. Ilin, D. Wang, B. MacDougall, Surf. Sci. 2006, 600, 3502-3511.

[32] C. Bock, C. Paquet, M. Couillard, G. A. Botton, B. R. MacDougall, J. Am. Chem. Soc. 2004, 126, 8028-8037.

[33] E. Morsbach, E. Brauns, T. Kowalik, W. Lang, S. Kunz, M. Baumer, Phys. Chem. Chem. Phys. 2014, 16, 21243-21251.

[34] a) I. Schrader, S. Neumann, R. Himstedt, A. Zana, J. Warneke, S Kunz, ChemComm. 2015, 51, 16221-16224; b) I. Schrader, S. Neumann, A. Sulce, F. Schmidt, V. Azov, S. Kunz, ACS Catal. 2017, 7, 3979-3987; c) I. Schrader, J. Warneke, J. Backenkohler, S. Kunz, J. Am. Chem. Soc. 2015, 137, 905-912.

[35] B. L. He, Y. X. Chen, H. F. Liu, Y. Liu, J. Nanosci. Nanotechnol. 2005, 5, 266-270

[36] Y. Y. Zheng, Z. J. Dou, Y. X. Fang, M. W. Li, X. Wu, J. H. Zeng, Z. H. Hou, S. J. Liao, J. Power Sources 2016, 306, 448-453.

[37] Y. J. Wang, N. N. Zhao, B. Z. Fang, H. Li, X. T. T. Bi, H. J. Wang, RSC Adv. 2015, 5, 56570-56577.

[38] a) S. Calvin, M. M. Miller, R. Goswami, S. F. Cheng, S. P. Mulvaney, L. J. Whitman, V. G. Harris, J. Appl. Phys. 2003, 94, 778-783; b) J. M. Montejano Carrizales, F. Aguilera Granja, J. L. Moran Lopez, Nanostruct. Mater. 1997, 8, 269-287.

[39] L. Kacenauskaite, J. Quinson, H. Schultz, J. J. K. Kirkensgaard, S. Kunz, T. Vosch, M. Arenz, ChemNanoMat 2017, 2, 89-93.

[40] M. Nishioka, M. Miyakawa, Y. Daino, H. Kataoka, H. Koda, K. Sato, T. M. Suzuki, Chem. Lett. 2011, 40, 1327-1329.

[41] L. Kacenauskaite, A. A. Swane, J. J. K. Kirkensgaard, M. Fleige S. Kunz, T. Vosch, M. Arenz, ChemNanoMat 2016, 2, 104-107.

[42] C. Jimenez-Gonzalez, P. Poechlauer, Q. B. Broxterman, B. S Yang, D. A. Ende, J. Baird, C. Bertsch, R. E. Hannah, P. Dell'Orco, H. Noorrnan, S. Yee, R. Reintjens, A. Wells, V. Massonneau, J. Manley, Org. Process Res. Dev. 2011, 15, 900911.

[43] S. H. Chen, K. Kimura, J. Phys. Chem. B. 2001, 105, 5397-5403.

[44] M. Richter, A. Karschin, B. Spingler, P. C. Kunz, W. Meyer-Zaika, W. Klaui, Dalton Trans. 2012, 41, 3407-3413.

[45] T. Imai, Y. Abe, K. Nishio, R. Tamura, H. Shibata, T. Kineri, S. Tsukada, T. Gunji, Polym. J. 2013, 45, 540-544.

[46] E. A. Baquero, S. Tricard, J. C. Flores, E. de Jesus, B. Chaudret, Angew. Chem. 2014, 126, 13436-13440; Angew. Chem. Int. Ed. 2014, 53, 13220-13224.

[47] a) T. I. Paiva, T. Hashimoto, M. J. Plancha, G. E. Thompson, C. M. Rangel, in IV Iberian Symposium on Hydrogen, Fuel Cells and Advanced Batteries, Estoril, Portugal, June 26-28 2013, 2013; b) J. F. Huang, H. W. Yang, Anal. Chem. 2016, 88, 6403-6409.

[48] S. Neumann, S. Grotheer, J. Tielke, I. Schrader, J. Quinson, A. Zana, M. Oezaslan, M. Arenz, S. Kunz, J. Mater. Chem. A. 2017, 5, 6140-6145.

[49] R. R. Arvizo, S. Bhattacharyya, R. A. Kudgus, K. Giri, R. Bhattacharya, P. Mukherjee, Chem. Soc. Rev. 2012, 41, 29432970.

[50] M. Inaba, J. Quinson, M. Arenz, J. Power Sources 2017, 353, 1927.

[51] J. Speder, A. Zana, M. Arenz, Catal. Today 2016, 262, 82-89.

[52] M. Newville, J. Synchrotron Radiat. 2001, 8, 322-324. 


\section{Entry for the Table of Contents}

\section{FULL PAPER}

The Co4Cat process is a simple method to produce colloidal dispersions of precious metal nanoparticles with controlled properties in alkaline mono-alcohols. The Pt NPs obtained show long term dispersibility in water and aqueous buffers.

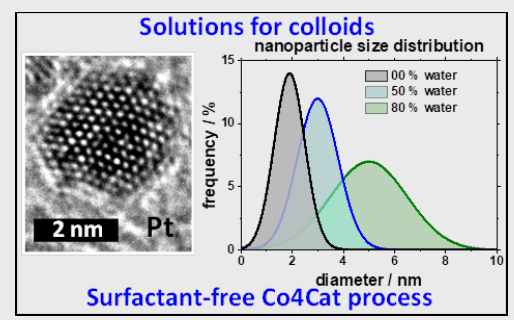

Author(s), Corresponding Author(s)*

Page No. - Page No.

Title 